\title{
Dietary fructose $v$. glucose in rats raises urinary excretion, true absorption and ileal solubility of magnesium but decreases magnesium retention
}

\author{
BY ANNET VAN DER HEIJDEN ${ }^{1}$, GERRIT J. VAN DEN BERG ${ }^{2}$, \\ ARNOLDINA G. LEMMENS ${ }^{1}$ AND ANTON C. BEYNEN ${ }^{1}$ \\ ${ }^{1}$ Department of Laboratory Animal Science, Utrecht University, 3508 TD Utrecht, The Netherlands \\ ${ }^{2}$ Interfaculty Reactor Institute, University of Technology, $2629 \mathrm{JB}$ Delft, The Netherlands
}

(Received 14 July 1993 - Revised 4 January 1994 - Accepted 1 February 1994)

\begin{abstract}
Apparent $\mathrm{Mg}$ absorption, that is $\mathrm{Mg}$ intake minus faecal excretion, was found to be greater in rats fed on diets containing fructose instead of glucose. This effect of fructose was accompanied by enhanced urinary excretion and diminished retention of $\mathrm{Mg}$. True $\mathrm{Mg}$ absorption was then determined with the use of oral and intraperitoneal administration of tracer doses of ${ }^{28} \mathrm{Mg}$. True $\mathrm{Mg}$ absorption was significantly greater in rats fed on fructose. There was no significant effect of fructose $v$. glucose on faecal excretion of endogenous $\mathrm{Mg}$. It was hypothesized that fructose enhances the solubility of $\mathrm{Mg}$ in the ileal lumen and thereby facilitates its absorption. The distribution of $\mathrm{Mg}$ between the solid and liquid phases of the ileum was determined in rats fed on either glucose or fructose. Fructose reduced the amount of $\mathbf{M g}$ in the solid phase but raised both the amount and the concentration of $\mathrm{Mg}$ in the liquid phase. We conclude that the dietary-fructose-induced stimulation of $\mathbf{M g}$ absorption in rats is caused by a raised solubility of ileal $\mathbf{M g}$, but the mechanism by which fructose exerts this effect and why it was not associated with a decrease in faecal excretion of endogenous $\mathrm{Mg}$ remain unknown. Dietary fructose $v$. glucose did not systematically affect the apparent absorption of $\mathrm{Ca}$ and $\mathrm{P}$.
\end{abstract}

Fructose: Magnesium: Absorption: Solubility: Rat

The amount of sucrose in the human diet, and thus also that of fructose, has increased dramatically during the last decades (Woteki et al. 1982). Since fructose $v$. glucose has been shown to raise apparent $\mathrm{Mg}$ absorption in humans (Holbrook et al. 1989), the increased intake of fructose could enhance $\mathrm{Mg}$ status which might be advantageous in relation to prevention of osteoporosis, hypertension, coronary heart disease and cancer (Shills, 1988). However, apparent $\mathrm{Mg}$ absorption is not always a valid index of $\mathrm{Mg}$ availability from the diet. Apparent $\mathrm{Mg}$ absorption is calculated as intake minus faecal excretion and thus includes faecal excretion of endogenous $\mathrm{Mg}$. For instance, replacement of soya-bean protein by casein in the diet of rats has been shown to raise apparent $\mathbf{M g}$ absorption but this was due to a decrease in faecal excretion of endogenous $\mathrm{Mg}$ (Brink et al. 1992 b). The mechanism underlying the enhancing effect of fructose on apparent $\mathrm{Mg}$ absorption is unknown (Brink \& Beynen, 1992), and theoretically it could be due to a decreased loss of endogenous $\mathrm{Mg}$. On the other hand, fructose could raise true $\mathrm{Mg}$ absorption. The amount of $\mathrm{Mg}$ absorbed depends on the concentration of soluble $\mathrm{Mg}$ in the ileal lumen (Brink et al. 1992a). If and when fructose improves true $\mathrm{Mg}$ absorption, it can be hypothesized that this is caused by raising the solubility of $\mathrm{Mg}$ in the intestine. In vitro experiments have indicated that fructose may form with $\mathrm{Mg}$ ions a stable, soluble chelate (Charley et al. 1963).

In the present studies with rats, two questions were addressed. First, does fructose $v$. 
glucose raise true fractional $\mathrm{Mg}$ absorption? We determined true $\mathrm{Mg}$ absorption with the use of the radiotracer ${ }^{28} \mathrm{Mg}$ which was administered orally or intraperitoneally. From the two retention curves of the administered isotope, true $\mathrm{Mg}$ absorption was calculated using the method of Heth \& Hoekstra (1965). Faecal excretion of endogenous Mg was calculated as the difference between true and apparent absorption. The second question was whether fructose influences the solubility of $\mathrm{Mg}$ in the intestine. We therefore examined the distribution of $\mathrm{Mg}$ between the solid and liquid phases of the ileal contents.

\title{
MATERIALS AND METHODS
}

The experimental protocols were approved by the animal experiments committee of the Department of Laboratory Animal Science, Utrecht University.

\section{Animals and housing}

Two separate experiments were carried out; the interval between them was 4 weeks. Outbred, male Wistar rats (Hsd/Cpb:WU; Harlan, Zeist, The Netherlands) aged 6 (Expt 1) or 3 (Expt 2) weeks were used. On arrival the rats were housed in groups of four animals in wire-topped, polycarbonate cages $(375 \times 225 \times 150 \mathrm{~mm})$ with a layer of sawdust as bedding. After 2 (Expt 1) or $6($ Expt 2) d the animals were housed individually in metabolism cages (Tecniplast Gazzada, Buguggiata, Italy). The cages were placed in a room with controlled temperature $\left(20-22^{\circ}\right)$, relative humidity $(40-65 \%)$ and light cycle (light, 06.00-18.00 hours). After the pre-experimental period (day 0) the rats were divided into two groups of either nine (Expt 1) or twelve (Expt 2) rats each so that body-weight distributions were similar. Each group was assigned randomly to one of the two experimental diets.

\begin{abstract}
Diets
On arrival the rats had ad lib. access to a commercial, pelleted diet (RMH-B ${ }^{\circledR}$; Hope Farms, Woerden, The Netherlands) and tap water. After 2 (Expt 1) or 4 (Expt 2) d the rats were transferred to the glucose diet (Table 1) and demineralized water for another $8 \mathrm{~d}$. Then (day 0), half of the rats were switched to the fructose diet. The composition of the diets is shown in Table 1. The diets contained either glucose (Morsweet 01934; Cerestar, Haubourdin, France) or fructose (Fruchtzucker Art. no. 0781 ; Südzucker AG, Mannheim/ Ochsenfurt, Germany) as the sole source of carbohydrate. Apart from the carbohydrate source the diets were formulated according to the nutrient requirements of rats (National Research Council, 1978). Separate batches of diet were used for each experiment. The purified diets, which were in powdered form, were stored at $4^{\circ}$ until feeding. Feed consumption and body weight were recorded weekly.

In Expt 1, food and demineralized water were freely available. For Expt 2 it was considered important to standardize the nutritional state of the rats because ileal digesta were to be collected. Thus, the animals were fed on a restricted basis. Each rat received an amount of food equivalent to $80 \%$ of ad lib. intake as based on earlier experiences. The food was provided in two meals of identical size, at 09.00 and 17.00 hours. The rats had free access to demineralized water. A period of $7 \mathrm{~d}$ (days -7 to 0 ) was used to accustom the animals to the feeding regimen.
\end{abstract}

\section{Radiotracer study}

For this study the older rats were used because true absorption of $\mathrm{Mg}$ in each rat had to be determined over an interval of $14 \mathrm{~d}$. It was expected that the efficiency of $\mathrm{Mg}$ absorption would drift with aging to a lesser extent in older rats. ${ }^{28} \mathrm{Mg}$ administrations (Expt 1) were performed on days 14 and 23 . On day 14, after overnight fasting, five animals from each 
Table 1. Composition of the experimental diets

\begin{tabular}{|c|c|c|c|c|}
\hline Diet... & \multicolumn{2}{|c|}{ Glucose } & \multicolumn{2}{|c|}{ Fructose } \\
\hline $\begin{array}{l}\text { Ingredients }(\mathrm{g} / \mathrm{kg}) \\
\text { Glucose } \\
\text { Fructose } \\
\text { Constant components* }\end{array}$ & \multicolumn{2}{|c|}{$\frac{709 \cdot 4}{290 \cdot 6}$} & \multicolumn{2}{|c|}{$\begin{array}{c}-- \\
709 \cdot 4 \\
290-6\end{array}$} \\
\hline & Expt 1 & Expt 2 & Expt 1 & Expt 2 \\
\hline $\begin{array}{l}\text { Calcium } \\
\text { Magnesium } \\
\text { Phosphorus }\end{array}$ & $\begin{array}{r}95 \\
14 \\
113\end{array}$ & $\begin{array}{r}115 \\
11 \\
139\end{array}$ & $\begin{array}{r}110 \\
15 \\
132\end{array}$ & $\begin{array}{r}115 \\
12 \\
139\end{array}$ \\
\hline
\end{tabular}

* The constant components consisted of ( $\mathrm{g} / \mathrm{kg}$ diet): casein 151 , maize oil 25 , coconut fat 25 , cellulose 30 , $\mathrm{CaCO}_{3} 12 \cdot 4, \mathrm{NaH}_{2} \mathrm{PO}_{4} \cdot 2 \mathrm{H}_{2} \mathrm{O} 15 \cdot 1, \mathrm{MgCO}_{3} 1 \cdot 4, \mathrm{KCl} 1 \cdot 0, \mathrm{KHCO}_{3} 7 \cdot 7$, mineral premix 10 , vitamin premix 12. The mineral premix consisted of the following (mg): $\mathrm{MnO}_{2} 79, \mathrm{FeSO}_{4} .7 \mathrm{H}_{2} \mathrm{O} 174, \mathrm{ZnSO}_{4} \cdot \mathrm{H}_{2} \mathrm{O} 33, \mathrm{NiSO}_{4} \cdot 6 \mathrm{H}_{2} \mathrm{O} 13$, $\mathrm{NaF} 2, \mathrm{CrCl}_{3} .6 \mathrm{H}_{2} \mathrm{O} 1 \cdot 5, \mathrm{SnCl}_{2} .2 \mathrm{H}_{2} \mathrm{O} 1 \cdot 9, \mathrm{NH}_{4} \mathrm{VO}_{3} 0 \cdot 2, \mathrm{KI} 0 \cdot 2, \mathrm{Na}_{2} \mathrm{SeO}_{3} .5 \mathrm{H}_{2} \mathrm{O} 0 \cdot 3, \mathrm{CuSO}_{4} .5 \mathrm{H}_{2} \mathrm{O} 15 \cdot 7$, maize meal 9679-2. The vitamin premix consisted of the following $(\mathrm{mg})$ : thiamin 4 , riboflavin 3 , nicotinamide 20 , DLcalcium panthothenic acid $17 \cdot 8$, pyridoxine 6 , cyanocobalamin 50 , choline chloride 2000 , pteroylmonoglutamic acid 1 , biotin 2, menadione 0.05 , DL-alpha tocopheryl acetate 60 , retinyl acetate and retinyl palmitate $8(1200$ retinol equivalents), cholecalciferol 0.025 , maize meal $9828 \cdot 125$.

dietary group received $\left[{ }^{28} \mathrm{Mg} \mathrm{MgCl}_{2}\right.$ (Interfaculty Reactor Institute, University of Technology, Delft, The Netherlands) with an extrinsically labelled meal. The remaining four animals of each group were injected with the radiotracer intraperitoneally. To equalize handling and treatment of each rat, the rats receiving the radiotracer orally were injected intraperitoneally with distilled water and the rats that were injected with ${ }^{28} \mathrm{Mg}$ were given a meal without the radiotracer. On day 23 the route of administration of radiotracer for each animal was alternated. On the days of radiotracer administration, treatment order of the rats was randomized.

The radioactive meals were prepared by adding $100 \mu 1 \quad 163 \cdot 2 \mathrm{mM}\left[{ }^{28} \mathrm{Mg}_{\mathrm{MgCl}}\right.$ $(1.2 \mathrm{GBq} / \mathrm{mol})$ in distilled water to $2 \mathrm{~g}$ experiment diet. For intraperitoneal administration the $100 \mu 1$ of radiotracer solution was injected. The meals with or without radiotracer were presented to the rats after $16 \mathrm{~h}$ without access to food. The meals were consumed within $5 \mathrm{~min}$. Subsequently the intraperitoneal injection was given. Radioactivity in individual rats was counted in a specially designed whole-animal gamma scintillation detector (Barneveld \& Van den Hamer, 1984) within 5 min after administration of ${ }^{28} \mathrm{Mg}$. Thereafter all rats received their normal diets. For another $4 \mathrm{~d}$ the animals were counted for radioactivity every $8 \mathrm{~h}$. All animals were also measured on day 22, $1 \mathrm{~d}$ before the second administration of the radiotracer; whole-body radioactivity was found not to differ from background measurements. The efficiency of the whole-body counter for detection of ${ }^{28} \mathrm{Mg}$ was $65 \%$, and its stability was monitored by counting a ${ }^{65} \mathrm{Zn}$ source.

\section{Collection of ileal digesta}

On day 14 (Expt 2), $2.5 \mathrm{~h}$ after their morning meal, the rats were anaesthetized by exposure to diethyl ether. Blood was obtained by orbital puncture and the rats were immediately killed by cervical dislocation. The entire small intestine, between stomach and caecum, was removed. The contents in the distal half of the intestine were collected in pre-weighed centrifuge tubes by gently squeezing the intestine between finger and thumb. The ileum was chosen for measurement of $\mathrm{Mg}$ solubility because this intestinal segment is most prominent in $\mathrm{Mg}$ absorption (Hardwick et al. 1991). The intestinal contents were immediately 
centrifuged $(10 \mathrm{~min}, 10000 \mathrm{~g})$, and supernatant and pellet were separated. The weights of pellet and supernatant were determined. The $\mathrm{pH}$ of the supernatant was measured directly (Russell combination pH electrode, Type RS-53; Auchtermuchty, Fife).

\section{Collection of faeces and urine}

From day 14-18 and day 23-27 (Expt 1) and day 10-13 (Expt 2), urine and faeces of each rat were collected quantitatively. The cages and tubes for collection of faeces and urine had been washed with phosphate-free detergent and rinsed thoroughly with $0 \cdot 1 \mathrm{M}-\mathrm{HCl}$ and demineralized water. To block bacterial and mould growth, $100 \mu \mathrm{l}$ of a $308 \mathrm{mM}-\mathrm{NaN}_{3}$ solution was added daily to the urine collecting tubes.

\section{Chemical analyses}

Faeces and ileal pellets were freeze-dried overnight, homogenized and weighed. A sample of $150 \mathrm{mg}$ was ashed at $500^{\circ}$ for $17 \mathrm{~h}$ and dissolved in $6 \mathrm{M}-\mathrm{HCl}$. Feed samples $(750 \mathrm{mg})$ were processed in the same way. To $50 \mu \mathrm{l}$ ileal supernatant, $450 \mu \mathrm{l} 5 \%(\mathrm{w} / \mathrm{v})$ trichloroacetic acid (TCA) was added and the TCA-soluble fraction was obtained by centrifugation ( 2 min, $10000 \mathrm{~g}$ ). Of the urine, $5 \mathrm{ml}$ was acidified with $1 \mathrm{ml} 6 \mathrm{M}-\mathrm{HCl}$ and centrifuged $(10 \mathrm{~min}$, $1200 \mathrm{~g}$ ). The supernatant and the remaining nonacidified urine were frozen at $-20^{\circ}$ until further analysis. Plasma was collected from the heparinized blood samples by centrifugation.

$\mathrm{Ca}$ and $\mathrm{Mg}$ were determined in feed samples, plasma, urine, faeces and ileal contents in the presence of $41 \mathrm{mM}-\mathrm{LaCl}_{3}$ with a Varian atomic absorption spectrophotometer type AA475C (Varian Techtron, Springvale, Australia). Phosphate was determined with the use of a commercial test combination (Phosphate, MA-KIT 10 ROCHE; Roche Diagnostics, Basel, Switzerland) and a COBAS-BIO auto-analyser (Hoffmann-La Roche BV, Mijdrecht, The Netherlands). For complete recovery of phosphate from the ashed samples, analysis was performed at least 1 week after dissolution. Urinary creatinine concentrations were determined with the use of a commercial test combination (Creatinine, MA-KIT 10 ROCHE; Roche Diagnostics) and the auto-analyser.

\section{Calculations}

The distribution of minerals between the solid and liquid phases of ileal contents was calculated. The pellet obtained after centrifugation of the ileal contents comprises the solid phase contaminated with liquid phase. The weight of the solid phase was obtained after freeze-drying the pellet. The weight of the liquid phase was calculated as the sum of the weight of liquid phase in the pellet ( = total pellet weight minus solid phase) and that of supernatant. The concentration of minerals in the supernatant was assumed to be identical to that in the liquid phase. The amount of minerals in the solid phase was calculated as that in the total pellet minus that in the liquid phase of the pellet. Multiplying mineral concentration (mM) in the supernatant by the weight of the liquid phase gave the amount of minerals in the liquid phase.

Apparent absorption of minerals was calculated as mineral intake minus faecal excretion and expressed as a percentage of intake. Retention of minerals was calculated as mineral intake minus faecal-plus-urinary excretion.

True $\mathrm{Mg}$ absorption was calculated according to Heth \& Hoekstra (1965). Counting measurements were corrected for background and radioisotope decay, and then expressed as a percentage of the administered dose. Plots of the logarithm of percentage radioactivity retention after intraperitoneal and oral ${ }^{28} \mathrm{Mg}$ administration $\boldsymbol{v}$. time were constructed. The zero-time intercepts were determined by extrapolating the linear parts of the curves. Percentage true absorption was calculated by dividing the intercept of the retention curve for oral ${ }^{28} \mathrm{Mg}$ by that of the retention curve for intraperitoneal ${ }^{28} \mathrm{Mg}$ and multiplying by 
Table 2. Growth performance and excreta production of rats fed on diets containing glucose or fructose as the sole carbohydrate source $\ddagger$

(Mean values with their standard errors for nine (Expt 1) or twelve (Expt 2) rats per dietary group)

\begin{tabular}{|c|c|c|c|c|c|c|c|c|}
\hline & \multicolumn{4}{|c|}{ Expt 1} & \multicolumn{4}{|c|}{ Expt 2} \\
\hline & \multicolumn{2}{|c|}{ Glucose } & \multicolumn{2}{|c|}{ Fructose } & \multicolumn{2}{|c|}{ Glucose } & \multicolumn{2}{|c|}{ Fructose } \\
\hline & Mean & $\mathrm{SE}$ & Mean & $\mathbf{S E}$ & Mean & $\mathrm{sE}$ & Mean & $\overline{\mathrm{SE}}$ \\
\hline \multicolumn{9}{|l|}{ Body wt } \\
\hline Initial (g) & 224 & $3 \cdot 2$ & 224 & $2 \cdot 8$ & 102 & $1 \cdot 1$ & 102 & $1 \cdot 2$ \\
\hline Final† (g) & 289 & $5 \cdot 3$ & 288 & $2 \cdot 7$ & 149 & $1 \cdot 2$ & 149 & 1.4 \\
\hline Feed intake§ $(\mathrm{g} / \mathrm{d})$ & $16 \cdot 7$ & $0 \cdot 2$ & $17 \cdot 2$ & 0.2 & 10 & & 10 & \\
\hline \multicolumn{9}{|l|}{ Faeces } \\
\hline Production $(\mathrm{g} / \mathrm{d})$ & 1.56 & 0.05 & 1.67 & 0.08 & 0.49 & 0.03 & 0.50 & 0.03 \\
\hline Dry matter $(\mathrm{g} / \mathrm{kg})$ & 542 & 21 & 526 & 14 & 791 & 17 & 775 & 12 \\
\hline \multicolumn{9}{|l|}{ Urine } \\
\hline Production $(\mathrm{ml} / \mathrm{d})$ & \multicolumn{2}{|c|}{ NPף } & \multicolumn{2}{|c|}{ NPq } & $6 \cdot 3$ & $1 \cdot 3$ & $4 \cdot 6$ & 0.8 \\
\hline pH & $8 \cdot 7$ & 0.2 & 7.8 & 0.4 & $8 \cdot 5$ & $0 \cdot 1$ & $7 \cdot 5^{*}$ & 0.1 \\
\hline
\end{tabular}

NP, not presented.

Mean value was significantly different from that of the glucose group: ${ }^{*} P<0.05$.

$\dagger$ For details of diets and procedures, see Table 1 and pp. 568-570.

\# Expt 1, day 28; Expt 2, day 14 .

$\S$ In Expt 2 the animals were fed on a restricted basis and thus SE values are not given.

I Not presented because urine collection was incomplete due to whole-body counting.

100. This calculation was executed for each animal. True $\mathrm{Mg}$ absorption in $\mathrm{mg}$ was calculated by multiplying $\mathrm{Mg}$ intake by percentage true $\mathrm{Mg}$ absorption.

Faecal excretion of endogenous $\mathrm{Mg}$ was calculated as true absorption in $\mathrm{mg}$ minus apparent absorption of $\mathbf{M g}$ in $\mathrm{mg}$.

\section{Statistical analyses}

The equations for the radioactivity retention curves were fitted using the least squares method. Within the dietary groups of Expt 1, the results of radiotracer administration on day $14 v$. day 23, including the slopes of the retention curves for the same administration route, were not significantly different (Student's $t$ test), and thus the data were pooled. The same held for the results of the two balance periods in Expt 1. Differences between group means were evaluated with Student's $t$ test when the data were normally distributed and with Wilcoxon's rank sum test when the data were not normally distributed. Data within groups were checked for normality with the Kolmogorov-Smirnov test. The variances of the treatment groups were tested for heterogeneity using Fisher's $F$ test. In cases of homogeneity the pooled variance estimates were used, and in cases of heterogeneity we used the separate variance estimates in the Student's $t$ test. The level of significance was preset at $P<0.05$.

\section{RESULTS}

\section{Body weight and excreta production}

Within each experiment, final body weight and faeces production did not differ significantly between the dietary groups (Table 2). In Expt 2, urine production by the glucose and fructose groups was similar. The older rats in Expt 1 produced faeces with a higher water 
Table 3. Apparent absorption and urinary excretion of $\mathrm{Mg}, \mathrm{Ca}$ and $\mathrm{P}$ in rats fed on diets containing glucose or fructose as the sole carbohydrate source $\dagger$

(Mean values with their standard errors for nine (Expt 1) or twelve (Expt 2) rats per dietary group)

\begin{tabular}{|c|c|c|c|c|c|c|c|c|}
\hline & \multicolumn{4}{|c|}{ Expt $1 \ddagger$} & \multicolumn{4}{|c|}{ Expt $2 \S$} \\
\hline & \multicolumn{2}{|c|}{ Glucose } & \multicolumn{2}{|c|}{ Fructose } & \multicolumn{2}{|c|}{ Glucose } & \multicolumn{2}{|c|}{ Fructose } \\
\hline & Mean & $\mathrm{SE}$ & Mean & $\mathrm{SE}$ & Mean & $\mathrm{SE}$ & Mean & $\mathrm{SE}$ \\
\hline \multicolumn{9}{|l|}{ Magnesium } \\
\hline Intake $(\mathrm{mmol} / \mathrm{d})$ & 0.21 & 0.01 & $0.24 *$ & 0.01 & \multicolumn{2}{|c|}{0.12} & \multicolumn{2}{|c|}{0.12} \\
\hline Absorption (\%) & $36 \cdot 4$ & $4 \cdot 5$ & $57 \cdot 4 *$ & 1.8 & $76 \cdot 0$ & $1 \cdot 7$ & $82 \cdot 0^{*}$ & $1 \cdot 4$ \\
\hline $\begin{array}{l}\text { Urine }(\mu \mathrm{mol} / \mu \mathrm{mol} \\
\text { creatinine (Expt 1) } \\
\text { or } \mu \mathrm{mol} / \mathrm{d}(\text { Expt } 2))\end{array}$ & $0 \cdot 47$ & $0 \cdot 09$ & $0.80^{*}$ & 0.12 & $17 \cdot 7$ & $2 \cdot 3$ & $39 \cdot 1 *$ & $2 \cdot 3$ \\
\hline \multicolumn{9}{|l|}{ Calcium } \\
\hline Intakeף $(\mathrm{mmol} / \mathrm{d})$ & 1.53 & $0 \cdot 04$ & $1.71^{*}$ & 0.04 & \multicolumn{2}{|c|}{$1 \cdot 15$} & \multicolumn{2}{|c|}{$1 \cdot 15$} \\
\hline Absorption (\%) & $25 \cdot 2$ & $5 \cdot 7$ & $34 \cdot 7$ & $3 \cdot 1$ & $64 \cdot 1$ & $1 \cdot 2$ & $62 \cdot 5$ & $2 \cdot 6$ \\
\hline $\begin{array}{l}\text { Urine }(\mu \mathrm{mol} / \mu \mathrm{mol} \\
\text { creatinine }(\text { Expt 1) } \\
\text { or } \mu \mathrm{mol} / \mathrm{d}(\text { Expt } 2))\end{array}$ & 0.09 & 0.03 & 0.09 & 0.01 & $5 \cdot 5$ & 0.6 & $8 \cdot 5^{*}$ & $1 \cdot 2$ \\
\hline \multicolumn{9}{|l|}{ Phosphorus } \\
\hline Intakef $(\mathrm{mmol} / \mathrm{d})$ & 1.83 & 0.04 & $2.05^{*}$ & 0.05 & \multicolumn{2}{|c|}{1.39} & \multicolumn{2}{|c|}{1.39} \\
\hline Absorption (\%) & $58 \cdot 7$ & $3 \cdot 2$ & $71 \cdot 3^{*}$ & 1.7 & $83 \cdot 8$ & 0.9 & $84 \cdot 9$ & $1 \cdot 3$ \\
\hline $\begin{array}{l}\text { Urine }(\mu \mathrm{mol} / \mu \mathrm{mol} \\
\text { creatinine (Expt 1) } \\
\text { or } \mu \mathrm{mol} / \mathrm{d}(\text { Expt } 2))\end{array}$ & $10 \cdot 7$ & $1 \cdot 3$ & $14 \cdot 4$ & 1.9 & 352 & 17 & 400 & 14 \\
\hline
\end{tabular}

Mean value was significantly different from that of the glucose group: ${ }^{*} P<0.05$.

$\dagger$ For details of diets and procedures, see Table 1 and pp. 568-570.

$\ddagger$ Average values for days $14-18$ and $23-27$.

$\S$ Days 10-13.

If In Expt 2 the animals were fed on a restricted basis and thus SE values are not given.

content than the younger rats in Expt 2. Fructose feeding instead of glucose feeding lowered urinary $\mathrm{pH}$.

\section{Apparent absorption of minerals}

In Expt $1, \mathrm{Mg}, \mathrm{Ca}$ and $\mathrm{P}$ intakes were significantly higher in the fructose group. This is explained by the greater group mean food intake and higher dietary mineral concentrations for the fructose group in Expt 1. In Expt 2, in which the rats were given a restricted amount of food, there were no group differences in mineral intake. In the two experiments the fructose diet significantly raised apparent $\mathrm{Mg}$ absorption, which was associated with increased urinary excretion of $\mathbf{M g}$ (Table 3). Urinary $\mathbf{M g}$ values in Expt 1 are expressed relative to urinary creatinine because urine collection was incomplete as a result of wholebody counting. Apparent absorption of $\mathrm{Ca}$ was not affected by fructose $v$. glucose in the diet. In Expt 2, Ca excretion in urine was raised by fructose. In Expt 1, but not in Expt 2, the apparent absorption of $\mathbf{P}$ was significantly enhanced in the fructose group. In Expt 1 , mineral absorption efficiencies were markedly lower than in Expt 2.

\section{Plasma minerals}

In Expt 2, plasma mineral concentrations were measured. Fructose $v$. glucose caused significantly increased plasma $P$ concentrations (2.32 (SE 0.05) v. 2.05 (SE 0.05) mM, $n$ 12) but did not alter $\mathrm{Ca}$ and $\mathrm{Mg}$ concentrations (1.83 (SE 0.02) v. 1.82 (SE 0.02) $\mathrm{mM}$ and 0.55 (SE 0.02) v. 0.59 (SE 0.02) $\mathrm{mm}$ respectively). 


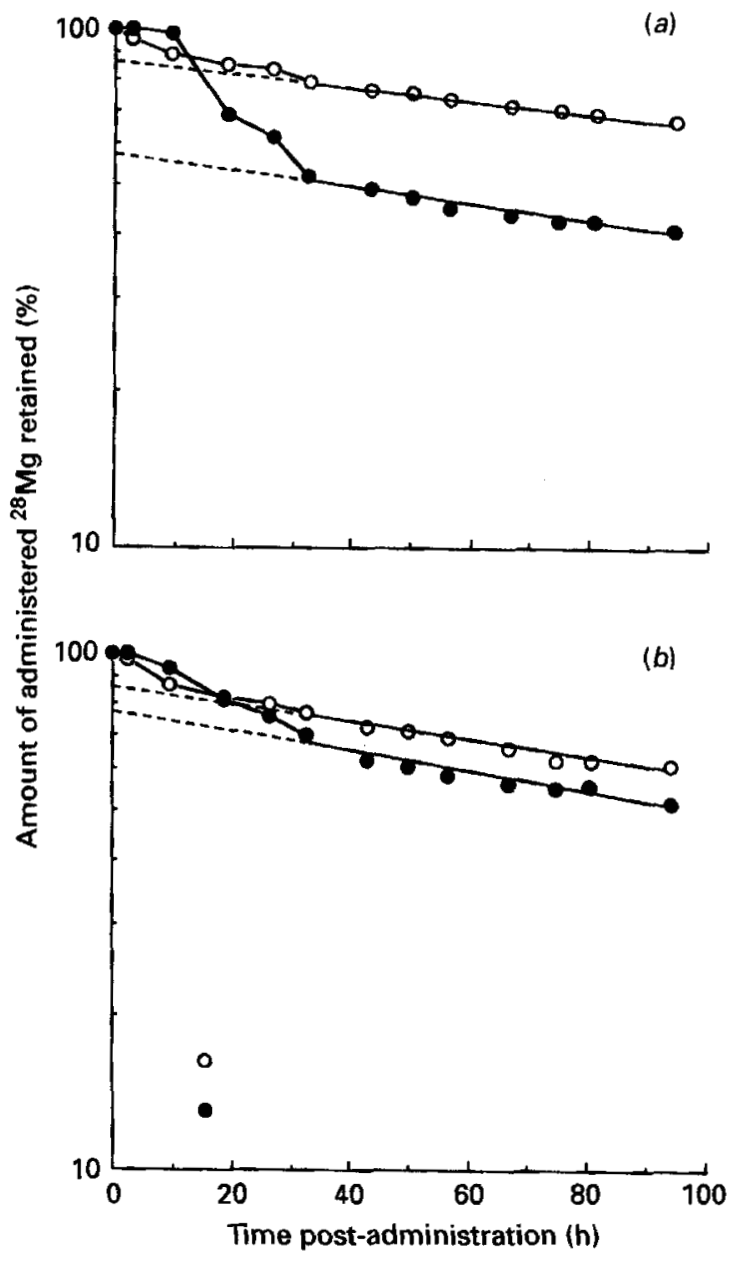

Fig. 1. Retention curves for radioactivity in rats fed on dicts containing either glucose $(a)$ or fructose $(b)$ after oral $(O)$ and intraperitoneal $(O)$ administration of ${ }^{28} \mathrm{Mg}$. Data are presented as means for nine rats per dietary group. Linear regression equations for each curve were established for the seven timepoints beyond $33 \mathrm{~h}$ postadministration. Glucose diet, intraperitoneal: $\log y=-1 \cdot 15 \times 10^{-3}\left(\mathrm{SE} 5.7 \times 10^{-5}\right) x+1.93\left(\mathrm{SE} 5.3 \times 10^{-3}\right)$; oral: $\log$ $y=-1.58 \times 10^{-3}\left(\mathrm{SE} 8.5 \times 10^{-5}\right) x+1.76\left(\mathrm{SE} 1.6 \times 10^{-2}\right)$. Fructose diet, intraperitoneal: $\log y=-1.61 \times 10^{-3}$ (SE $\left.1 \cdot 1 \times 10^{-4}\right) x+1.93\left(\right.$ SE $\left.7.3 \times 10^{-3}\right)$; oral: $\log y=-1.86 \times 10^{-3}\left(\right.$ SE $\left.1.0 \times 10^{-4}\right) x+1.88\left(\right.$ SE $\left.1.3 \times 10^{-2}\right)$.

\section{True $\mathrm{Mg}$ absorption}

For both dietary treatments in Expt 1 the semi-logarithmic retention curves for orally and intraperitoneally administered ${ }^{28} \mathrm{Mg}$ are presented in Fig. 1 . In rats fed on fructose, true $\mathrm{Mg}$ absorption was significantly higher than in rats fed on glucose (Table 4). There was no statistically significant carbohydrate effect on the excretion of endogenous $\mathrm{Mg}$.

\section{Minerals in ileal digesta}

In Expt 2, rats fed on fructose had a significantly larger liquid-phase volume in their ileal contents than rats fed on glucose (Table 5). Fructose feeding significantly raised the $\mathrm{pH}$ of the liquid phase. In rats fed on the fructose diet the amount of $\mathrm{Mg}$ in the solid phase was significantly reduced, but that in the liquid phase was raised. The concentration of $\mathrm{Mg}$ in the liquid phase was significantly elevated in rats fed on fructose (Table 5). After feeding 
Table 4. Expt 1. Influence of fructose $\mathrm{v}$. glucose on true $\mathrm{Mg}$ absorption and loss of endogenous $\mathrm{Mg}$ in the rat $\$$

(Mean values with their standard errors for nine rats per dietary group)

\begin{tabular}{ccccccc}
\hline & \multicolumn{2}{c}{ Glucose } & & \multicolumn{2}{c}{ Fructose } \\
& Mean & SE & & Mean & SE \\
\hline True absorption $(\%)$ & & $67 \cdot 1$ & $2 \cdot 4$ & & $89 \cdot 0^{*}$ & $2 \cdot 2$ \\
Endogenous loss $(\mu \mathrm{mol} / \mathrm{d})$ & & $65 \cdot 8$ & $9 \cdot 6$ & & $74 \cdot 1$ & $5 \cdot 5$ \\
\hline
\end{tabular}

Mean value was significantly different from that of the glucose group: $* P<0.05$

+ For details of diets and procedures, see Table 1 and pp. 568-571.

$\ddagger$ True $\mathrm{Mg}$ absorption was calculated on the basis of ${ }^{28} \mathrm{Mg}$ retention after radiotracer administration on days 14 and 23. Loss of endogenous $\mathrm{Mg}$ was calculated from true and apparent absorption, the latter being the average value for days 14-18 and 23-27.

Table 5. Expt 2. Distribution of minerals between the liquid and solid phases of the ileal lumen in rats fed on diets containing glucose or fructose as the sole carbohydrate source $\dagger$

(Mean values with their standard errors for twelve rats per dietary group)

\begin{tabular}{|c|c|c|c|c|}
\hline & \multicolumn{2}{|c|}{ Glucose } & \multicolumn{2}{|c|}{ Fructose } \\
\hline & Mean & SE & Mean & SE \\
\hline \multicolumn{5}{|l|}{ Intestinal content $\ddagger$} \\
\hline Solid phase wt (g) & 0.078 & $0-009$ & 0.066 & 0.005 \\
\hline Liquid phase wt (g) & $0 \cdot 314$ & 0.030 & $0.414^{*}$ & 0.017 \\
\hline $\mathrm{pH}$ of liquid phase & $7 \cdot 56$ & 0.06 & $7 \cdot 83^{*}$ & 0.05 \\
\hline \multicolumn{5}{|l|}{ Magnesium } \\
\hline Amount in solid phase ( $\mu \mathrm{mol})$ & $10 \cdot 4$ & 0.7 & $2 \cdot 5^{*}$ & 0.5 \\
\hline Amount in liquid phase $(\mu \mathrm{mol})$ & $2 \cdot 3$ & 0.1 & $4 \cdot 0^{*}$ & 0.3 \\
\hline Concentration in liquid phase (mM) & $7 \cdot 7$ & 0.5 & $10 \cdot 0^{*}$ & 0.8 \\
\hline \multicolumn{5}{|l|}{ Calcium } \\
\hline Amount in solid phase $(\mu \mathrm{mol})$ & $87 \cdot 8$ & $7 \cdot 3$ & $58 \cdot 4^{*}$ & $9 \cdot 2$ \\
\hline Amount in liquid phase $(\mu \mathrm{mol})$ & $4 \cdot 5$ & $1 \cdot 2$ & $8 \cdot 2 *$ & 0.6 \\
\hline Concentration in liquid phase (mM) & $13 \cdot 0$ & $2 \cdot 5$ & $20 \cdot 3^{*}$ & $1 \cdot 7$ \\
\hline \multicolumn{5}{|l|}{ Phosphorus } \\
\hline Amount in solid phase $(\mu \mathrm{mol})$ & $60 \cdot 4$ & 40 & $23 \cdot 2^{*}$ & $4 \cdot 6$ \\
\hline Amount in liquid phase $(\mu \mathrm{mol})$ & $2 \cdot 6$ & 0.5 & $0.6 *$ & 0.1 \\
\hline Concentration in liquid phase (mM) & $8 \cdot 1$ & 1.6 & $1 \cdot 8^{*}$ & 0.3 \\
\hline
\end{tabular}

Mean value was significantly different from that of the glucose group: ${ }^{*} \boldsymbol{P}<0.05$.

$\dagger$ For details of diets and procedures, see Table 1 and pp. 568-570.

$\ddagger$ Ileal digesta was collected on day 14 of the experiment.

the fructose diet, the concentration of $\mathrm{Ca}$ in the liquid phase was raised significantly, but that of $\mathbf{P}$ was reduced. The total amount of $\mathrm{Mg}, \mathrm{Ca}$ and $\mathbf{P}$ in ileal digesta was lowered in rats given fructose.

\section{DISCUSSION}

In the two experiments, dietary fructose $v$. glucose stimulated the apparent absorption of $\mathrm{Mg}$. This fructose effect is in accordance with other experiments in rats (Brink \& Beynen, 1992) and humans (Holbrook et al. 1989). The efficiency of $\mathrm{Mg}$ absorption was higher in 
Expt 2 than in Expt 1, which may either relate to the younger age of the rats used in Expt 2 or to the fact that these rats were given a restricted amount of diet. In Expt 1, older, slowly growing rats were used whereas in Expt 2 the rats grew more rapidly. Nevertheless, the stimulatory effect of fructose on apparent $\mathrm{Mg}$ absorption was seen in both experiments. The major objective of this study was to find out whether fructose stimulates true $\mathrm{Mg}$ absorption and why it would do so.

As in earlier work (Brink et al. 1992b), true Mg absorption was measured with the use of oral and intraperitoneal administration of tracer doses of ${ }^{28} \mathrm{Mg}$. The initial loss of total body activity after oral administration of ${ }^{28} \mathrm{Mg}$ is caused by passage of the radiotracer through the intestine and its excretion in faeces. Compared with glucose in the diet, fructose markedly reduced the initial loss of label (Fig. 1). This indicates, as was indeed found after calculation (Table 4), that true $\mathrm{Mg}$ absorption was enhanced by fructose. Thus, the observed stimulatory effect of fructose on apparent absorption of $\mathrm{Mg}$ reflects true absorption rather than depressed loss of endogenous $\mathrm{Mg}$. In fact, faecal excretion of endogenous $\mathrm{Mg}$ was not affected by fructose in the diet.

Up to concentrations of $20 \mathrm{~mm}$ there is a direct relationship between soluble ileal $\mathrm{Mg}$ and apparent Mg absorption in rats (Brink et al. 1992a). Thus, we hypothesized that fructose enhances the ileal solubility of $\mathbf{M g}$ which in turn may elevate the amount of $\mathbf{M g}$ that can cross the intestinal epithelium. Indeed, we found that fructose $v$. glucose significantly raised the concentration of $\mathrm{Mg}$ in the liquid phase of the ileum. It is not known why dietary fructose raises the amount of soluble $\mathrm{Mg}$ in the intestine. Fructose $v$. glucose produced a significantly higher ileal $\mathrm{pH}$, but this would lower ileal $\mathrm{Mg}$ solubility (Heijnen et al. 1993). Possibly, in the intestine fructose can form with $\mathrm{Mg}$ ions a stable, soluble chelate as has been demonstrated under in vitro conditions (Charley et al. 1963). Fructose $v$. glucose markedly lowered the total amount of $\mathrm{Mg}$ in the ileal contents. The basis for this observation is unknown.

The form and site of entry of endogenous $\mathrm{Mg}$ into the intestinal tract are unknown. This makes it difficult to speculate on the effect, if any, of dietary fructose on the metabolism of endogenous $\mathrm{Mg}$. Nevertheless, it could be expected that dietary fructose not only raises the intestinal solubility of exogenous $\mathrm{Mg}$, but also solubilizes $\mathrm{Mg}$ from endogenous sources and thus stimulates reabsorption of endogenous $\mathrm{Mg}$. However, the fructose-induced stimulation of true $\mathrm{Mg}$ absorption was not associated with a decrease in faecal excretion of endogenous $\mathrm{Mg}$, suggesting that endogenous and exogenous $\mathrm{Mg}$ are not mixed indistinguishably in the intestine and thus behave differently. Perhaps this relates to the notion that dietary and endogenous $\mathrm{Mg}$ enter the digestive tract at different times and do not interact with ingested fructose in the same way. Another possitility could be that fructose enhances the excretion of endogenous $\mathrm{Mg}$ while at the same time stimulating endogenous $\mathrm{Mg}$ absorption, but this is not likely.

The observed rise in ileal $\mathrm{Mg}$ solubility in rats fed on fructose may not be causatively related to the increase in $\mathrm{Mg}$ absorption. Fructose feeding raised the volume of the ileal liquid phase, which may be caused by an osmolar action of fructose. This effect of fructose could result in distension of the intestine, causing opening of intercellular junctions and permitting a greater flow. As a consequence, $\mathrm{Mg}$ absorption by the paracellular route (Hardwick et al. 1991) would be enhanced. However, such a mechanism should also raise the reabsorption of endogenous $\mathrm{Mg}$. Thus, the alternative explanation for the fructoseinduced stimulation of $\mathrm{Mg}$ absorption also appears at variance with the unchanged faecal excretion of endogenous $\mathrm{Mg}$.

The stimulation of true $\mathrm{Mg}$ absorption in rats fed on fructose was accompanied by enhanced urinary excretion of $\mathbf{M g}$. Dietary fructose $v$. glucose produced a decreased urinary $\mathrm{pH}$, which confirms studies showing that fructose promotes acidosis (Bergström et 
al. 1968; Sahebjami \& Scalettar, 1971). The fructose-induced lowering of urinary $\mathrm{pH}$ may decrease tubular reabsorption of $\mathrm{Mg}$ (McDougal \& Koch, 1989) and may thus have contributed to the observed rise in urinary excretion of $\mathrm{Mg}$ in rats fed on fructose. Theoretically, it is possible that the stimulation of $\mathrm{Mg}$ absorption caused by fructose feeding is secondary to the enhanced loss of $\mathrm{Mg}$ in urine, but for such a mechanism there is no metabolic basis (Hardwick et al. 1991). Furthermore, acidifying the urine of rats by the feeding of $\mathrm{NH}_{4} \mathrm{Cl}$ caused stimulation of urinary excretion of $\mathrm{Mg}$ but did not affect apparent Mg absorption (Toothill, 1963; Kaup \& Greger, 1990). In Expt 2, retention of Mg was significantly lower after feeding fructose instead of glucose (53.3 (SE 2.1) v. 68.9 (SE 2.4) $\mu \mathrm{mol} / \mathrm{d}, n$ 12). Thus, the enhanced urinary excretion of $\mathrm{Mg}$ in rats fed on fructose was not fully compensated for by the stimulation of $\mathrm{Mg}$ absorption. This could imply that the net effect of fructose on $\mathrm{Mg}$ bioavailability is a decrease.

The concentration of soluble ileal $\mathrm{Ca}$ was also increased by the fructose diet. Apparent $\mathrm{Ca}$ absorption was not affected by fructose feeding, which agrees with earlier work in rats (Vaughan \& Filer, 1960). Since there is hormonally controlled, active transport of $\mathrm{Ca}$ across the intestinal epithelium (Wilkinson, 1976), ileal solubility of Ca may not be a limiting factor for $\mathrm{Ca}$ absorption. Apparent absorption of $\mathrm{P}$ was stimulated by fructose feeding in Expt 1, but not in Expt 2. However, in Expt 2 the concentration of $P$ in the liquid phase of the ileal content was significantly lowered. Possibly, there is no relation between soluble $\mathrm{P}$ concentration in the ileum and its apparent absorption. Alternatively, under the present conditions transport of $\mathrm{P}$ across the intestinal epithelium was saturated so that changes in $\mathrm{P}$ solubility could not influence absorption.

We conclude that the stimulation of apparent $\mathrm{Mg}$ absorption in rats fed on fructose instead of glucose, reflects improvement of true $\mathrm{Mg}$ absorption, which is caused by an increase in solubility of ileal $\mathrm{Mg}$. The basis for the fructose-induced rise in the amount of soluble $\mathrm{Mg}$ in the intestine and the reason why fructose feeding did not produce a fall of faecal excretion of endogenous $\mathrm{Mg}$ remain unknown. Fructose $v$. glucose feeding enhanced urinary excretion of $\mathrm{Mg}$ to a greater extent than $\mathrm{Mg}$ absorption so that it lowered the retention of $\mathrm{Mg}$.

We are grateful to C. Zegers (Interfaculty Reactor Institute) for the preparation of ${ }^{28} \mathrm{Mg}$.

\section{REFERENCES}

Barneveld, A. A. \& Van den Hamer, C. J. A. (1984) Intestinal passage of simultaneously administered ${ }^{64} \mathrm{Cu}$ and ${ }^{65} \mathrm{Zn}$ and the effect of feeding in mouse and rat. Nutrition Reports International 29, 173-182.

Bergström, J., Hultman, E. \& Roch-Norlund, A. E. (1968). Lactic acid accumulation in connection with fructose infusion. Acta Medica Scandinavica 184, 359-364.

Brink, E. J. \& Beynen, A. C. (1992). Nutrition and magnesium absorption: a review. Progress in Food and Nutrition Science 16, 125-162.

Brink, E. J., Beynen, A. C., Dekker, P. R., Van Beresteijn, E. C. H. \& Van der Meer, R. (1992a). Interaction of calcium and phosphate decreases ileal magnesium solubility and apparent magnesium absorption in rats. Journal of Nutrition 122, $580-586$.

Brink, E. J., Van den Berg, G. J., Van der Meer, R., Wolterbeek, H. Th., Dekker, P. R. \& Beynen, A. C. (1992b). Inhibitory effect of soybean protein vs. casein on apparent absorption of magnesium in rats is due to greater excretion of endogenous magnesium. Journal of Nutrition 122, 1910-1916.

Charley, P. J., Sarkar, B., Stitt, C. F. \& Saltman, P. (1963). Chelation of iron by sugars. Biochimica et Biophysica Acta 69, 313-321.

Hardwick, L. L., Jones, M. R., Brautbar, N. \& Lee, D. B. N. (1991). Magnesium absorption: mechanisms and the influence of vitamin D, calcium and phosphate. Journal of Nutrition 121, 13-23.

Heijnen, A. M. P., Brink, E. J., Lemmens, A. G. \& Beynen, A. C. (1993). Ideal pH and apparent absorption of magnesium in rats fed on diets containing either lactose or lactulose. British Journal of Nutrition 70, 747-756.

Heth, D. A. \& Hoekstra, W. G. (1965). Zinc-65 absorption and turnover in rats. Journal of Nutrition 85, $367-374$.

Holbrook, J. T., Smith, J. C. \& Reiser, S. (1989). Dietary fructose or starch: effects on copper, zinc, iron, manganese, calcium, and magnesium balances in humans. American Journal of Clinical Nutrition 49, $1290-1294$. 
Kaup, S. M. \& Greger, J. L. (1990). Effect of various chloride salts on the utilization of phosphorus, calcium and magnesium. Journal of Nutritional Biochemistry 1, 542-548.

McDougal, W. C. \& Koch, M. (1989). Effect of sulphate on calcium and magnesium homeostasis following urinary diversion. Kidney International 35, 105-115.

National Research Council (1978). Nutrient Requirements of Laboratory Animals, no. 10, 3rd ed. Washington DC: National Academy of Sciences.

Sahebjami, H. \& Scalettar, R. (1971). Effects of fructose infusion on lactate and uric acid metabolism. Lancet 1, 366-369.

Shils, M. E. (1988). Magnesium in health and disease. Annual Review of Nutrition $8,429.460$.

Toothill, J. (1963). The effect of certain dietary factors on the apparent absorption of magnesium by the rat. British Journal of Nutrition 17, 125-134.

Vaughan, O. W. \& Filer, L. J. (1960). The enhancing action of certain carbohydrates on the intestinal absorption of calcium in the rat. Journal of Nutrition 71, 10-14.

Wilkinson, R. (1976). Absorption of calcium, phosphorus and magnesium. In: Calcium, Phosphate and Magnesium Metabolism [B. E. C. Nordin, editor]. Edinburgh: Churchill Livingstone.

Woteki, C. E., Welsh, S. O., Raper, W. \& Marston, R. M. (1982). Recent trends and levels of dietary sugars and other caloric sweeteners. In: Metabolic Effects of Utilizable Carbohydrates [S. Reiser, editor]. New York, NY: Marcel Dekker. 